\title{
School-based Training for Novice Teachers in Vocational Colleges
}

\author{
Qi LUO (Corresponding author) \\ The Center of Teachers' Education and Development, \\ Tianjin University of Technology and Education \\ No.1310, Dagu Southern Road, Hexi District, Tianjin, China \\ Tel: 86-18920866712Ｅ-mail: 360048683@qq.com
}

Received: January 29, 2022 Accepted: February 20, 2022 Published: March 2, 2022

doi: 10.5296/jsss.v9i1.19612

URL: https://doi.org/10.5296/jsss.v9i1.19612

\begin{abstract}
With the development of the new era, Chinese society needs more high-quality workers, and puts forward new requirements for the high-quality development of vocational education. In order to ensure the sound development of vocational education, the key is to improve the professional level of teachers in Vocational Colleges through school-based training, especially school-based training for novice teachers from the aspects of teachers' morality, theoretical teaching, practical teaching and so on.
\end{abstract}

Keywords: vocational education, school-based training, novice teachers

\section{Introduction}

In the 21 st century, society is undergoing great development, transformation and adjustment. A new round of scientific, technological and industrial revolution has arrived. The vocational education that directly transports workers to the front line of production is related to the development of the whole social economy. The development of Chinese new era also puts forward new requirements for vocational education, that is, to develop high-quality vocational education and cultivate more high-quality talents. The development of vocational education is of great significance, and the quality of teachers in vocational colleges plays a decisive role in the quality of vocational education. However, at present, the quality of teachers in Vocational Colleges in China can't meet the needs of talent cultivation in the new era. Therefore, it is imperative to comprehensively strengthen the construction of teacher quality in vocational colleges, especially the training of young teachers in vocational colleges. 


\section{The Necessity of School-Based Training}

\subsection{The Situation of Chinese Social Reality}

At present, China has built the largest vocational education system in the world. According to statistics, in 2019, there were 11500 vocational education schools in China, with 28.571 million students. With the development of Chinese social economy, vocational education plays an important role in social development. In January 2019, the State Council issued the implementation plan of national vocational education reform, which defined the status of Vocational Education: vocational education and general education are two different types of education, with equal importance. However, in the current reality of China, the vocational education of China has not received the same attention as general higher education. This situation is inseparable from traditional ideas of China. Since a long time ago, China has been deeply influenced by Confucian culture, and the concept of "excellent talents will be officials of society" is deeply rooted in the mind of Chinese people. It is believed that excellent students should become social elites, which is, officials, and managers and so on, and those who do not study well should go to vocational colleges to become social blue collar workers. In society, people generally regard general universities as orthodox higher education, while vocational education has become a shelter for students with learning difficulties who can't go to university. However, social development is inseparable from high-quality vocational education and the cultivation of vocational talents. Therefore, we have to change this traditional prejudice, attach importance to vocational education. In order to realize it, we should start from improving the quality of teachers in vocational colleges. Therefore, the training for novice teachers is very necessary.

\subsection{The Demand of Teachers' Professional Growth}

The particularity of the teacher profession determines that the teacher's learning lasts for a lifetime. A qualified and excellent teacher must study all his life to be competent for the teacher profession. As Professor Tang Yuguang discussed in his research on Teachers' professional development, "good teachers can be produced only in the continuous process of normal education, new entry and in-service education." [Tang, 2008]. In China, the education and training of teachers is divided into pre service training, induction training and on-the-job training. "Pre service training lays the foundation for engaging in the teaching profession, and on-the-job training provides a guarantee for the improvement of teachers' quality." [Tang, 2008]. The most significant advantage of school-based training is to make use of the resources and strength of the colleges to adapt to the specific needs of teachers and make corresponding training. "The original intention of school-based training program is to solve the problem of separation between educational theory and practice". [Tang, 2008].School-based training for teachers is of great significance, which is related to the professional growth of a teacher. In China, pre service training refers to the normal education of the teachers. Induction training is the pre teaching job training of novice teachers, and the continuing education of teachers after work is on-the-job training.

Novice teachers have just arrived in a completely new environment. Due to the lack of professional skills and professional ability, they are confused about everything at the beginning 
of their career. As the British government pointed out in Education: an extended framework: "even with full and strict pre service training, there is still no important occupation in the world that can expect new employees to make full contributions immediately." [Shan, 2010]. Professor Tang Yuguang also studied and discussed the primary and secondary school new teachers: "It is a sudden and rapid change from normal students to formal teaching. They have been pushed from a learning environment with dependence and less responsibility to a post with a variety of missions and almost helpless. The problems they facing need to undergo a severe test for most people, even it is likely to be a frustrating experience for some others. Whether this stage can go through and grow smoothly will deeply affect the professional development in the future. "[Tang, 2008]. The direct purpose of school-based training for novice teachers is to make new teachers in Vocational Colleges quickly adapt themselves to the new working environment and lay the foundation for the professional growth of new teachers. The rapid professional growth of new teachers can also make them quickly become qualified teachers in vocational colleges, so as to improve the teaching ability of the whole vocational education and ensure the high-quality development of vocational education. "Whether a school has stamina depends on whether young teachers grow rapidly... In the long run, young teachers determine the future of our college." [Zhu, 1990]. In addition, this kind of centralized group training for new teachers is conducive to their mental health. Through school-based training, new teachers who are new to a strange environment can get to know new partners with similar interests, and their communication with each other is full of happiness and sense of achievement, so as to reduce psychological pressure and integrate them into the new surroundings and vocational education of the new era. Therefore, the fundamental purpose of the training for novice teachers is to improve the quality of teachers in Vocational Colleges and ensure the high-quality development of vocational education.

\section{Content of School-Based Training}

The school-based training for new teachers mainly includes introducing the school situation, school history, school running philosophy, school rules and regulations to new teachers, but the main focus is on the training of teachers' morality, theoretical teaching ability and practical teaching ability.

\subsection{Teachers' Morality Education}

An ancient Chinese Mozi said, "Virtue is the commander of talent, talent is the aid of virtue." Since ancient times, China has attached great importance to teachers' personal professional ethics. The role of teachers is not only a "teaching craftsman" who teaches skills, but also a combination of virtue and art, both teaching and educating young people. Chinese traditional culture and the professional characteristics of teachers determine that teachers should be a group of people with noble morality. Qualified teachers should first be morally qualified. Professor Shan Zhonghui discussed in an article on the characteristics and trends of teachers' professional development in China: "Whether it is the introduction of Western Normal Education in modern times or the introduction of Western teacher specialization in modern times, China has transplanted things at the institutional level such as educational institutions and systems, excluded the religious and utilitarian aspects of its specific educational contents, 
and retained the professional ethics and moral education focusing on educating their own conduct and self-cultivation in the professional development of Chinese traditional teachers, which determines Chinese future development In the professional development of teachers, different from the Western focus on the development of 'licensed' technical teachers' specialization, it will promote their own 'emotional' and more humanistic teachers' professional development ". [Shan, 2010]. Therefore, the training of teachers' ethics for new teachers in vocational colleges is the requirement of Chinese traditional culture and the development of new times. Because colleges and universities are the main cultural front with strong humanistic atmosphere, we should take the excellent traditional Chinese culture as the foundation in the training, arrange traditional Chinese culture teachers to lead new teachers to learn Chinese traditional culture, such as Confucian classics, the Doctrine of the Mean and so on, make new teachers achieve the learning of an accomplished person, understand the way of being a teacher, and internalize in the mind and externalize in the practice. In a word, the training for the novice teachers can make Chinese traditional culture lay the foundation for their professional ethics cultivation. Secondly, from the training, new teachers should establish the ideals and beliefs of contemporary vocational education and have the responsibility of training more high-quality technical and skilled talents in the new era. Through such training of teachers' ethics, new teachers can achieve strict self-discipline, standardize professional behavior, strengthen self-cultivation and cultivate teachers' noble ethics.

\subsection{Theoretical Teaching Ability Training}

The concept of cultivating talents in vocational colleges is to pay equal attention to students' knowledge and ability. The bounden duty of teachers in vocational colleges is still to teach and educate people, spread knowledge, spread culture and cultural innovation. Doing a good job in teaching is the basic requirement for teachers in vocational colleges. Therefore, the theoretical teaching ability of teachers in vocational colleges is still very important. The teachers in Vocational Colleges in China are basically graduates with masters or doctor's degree, which is different from the primary and secondary school teachers trained in teachers' professional ability in normal schools. These teachers have higher education level, but not all of them have the basic normal teaching skills. Most of them have just graduated from their universities and have to start teaching for their own students. They basically lack basic theoretical teaching ability. Therefore, new teachers in vocational colleges need to go through a certain transition period, adapt to the transformation of new roles, receive special training and pass the test to get their teaching certification before they can take up their post. When conducting systematic school-based training for new teachers, we should pay special attention to the training of new teachers' professional ability in all aspects of theoretical teaching. Through systematic lectures, new teachers are trained from the aspects of theoretical teaching standard, the standard and requirements of teaching documents and archives, PPT making and computer-aided teaching skills, cultivating young people in classroom teaching, teachers' etiquette standard, etc. Through this school-based centralized training, new teachers can understand the basic theoretical teaching technique and requirements. Secondly, excellent teachers from the college are invited to share and exchange experience with new teachers, so that new teachers can have a preliminary understanding of successful teaching and student management. Finally, the 
novice teachers are divided into groups according to their major to carry out simulated theoretical teaching activities. The instructors in the group evaluate the whole teaching process and give some reasonable guidance and advice to the novice teachers. Through the new teachers' lecture simulation, so that the new teachers can combine the teaching theory with the teaching practice gradually and learn more theoretical teaching skills deeply.

\subsection{Practical Teaching Ability Training}

With the market economy development of China and the deepening of reform and opening up policy, in order to meet the needs of participating in global industrial competition, the demand for high-quality workers in the new era is increasing day by day. The talent training goal of Vocational Colleges in China is to cultivate compound high-tech talents who understand both professional knowledge and operational skills. The teaching system of vocational colleges and universities in China is composed of theoretical teaching and practical teaching. The two parts are interdependent and inseparable, and have internal and close ties. Both of them serve the overall goal of talent training of vocational education. "Vocational education belongs to ability based education, and the cultivation of its vocational ability and vocational characteristics needs to be formed in vocational activities" [Deng, 2012]. Therefore, the development needs of the times have prompted vocational colleges to form the school running characteristics of paying equal attention to knowledge and skills, double qualified teachers. "By 2020, there were 1332000 full-time teachers in vocational colleges, 834000 full-time teachers in secondary vocational schools and 498000 full-time teachers in higher vocational schools. The total number of double qualified teachers is 455600 , and there are 264000 in secondary vocational schools, accounting for $31.5 \%$ of the full-time teachers in secondary vocational schools. There are 191000 people in higher vocational colleges, accounting for $39.7 \%$ of full-time higher vocational teachers." [Xie, 2021] Therefore, the needs of new era development urge vocational colleges to pay equal attention to knowledge and practical skills. The society need more graduate students with double certificates and double qualified teachers. Double qualified, that is, teachers should have the certificates of both theoretical teaching and practical teaching. The file of the CPC Central Committee and the State Council give opinions on comprehensively deepening the reform of teachers' quality construction in the new era on January 20, 2018 put forward: "comprehensively improve the quality of teachers in Vocational Colleges and build a high-quality double qualified teacher team. Continue to implement the plan for improving the quality of teachers in vocational colleges and lead all localities to establish a double qualified teacher team with exquisite skills and the combination of full-time and part-time teachers." [http: //www.gov.cn/zhengce/, 2018]. Double qualified teachers are the characteristics and focus of the construction of high quality teachers in higher vocational education. Vigorously strengthening the construction of "double qualified" teachers is the demand of social development. "For a long time, teachers in higher vocational colleges are mostly recruited from fresh graduates, which have the obvious characteristics of "one strong and two weak" with strong professional theory and weak professional practice ability and teaching practice ability. The teachers who account for a large proportion of this part are the short board of the "double qualified" teacher team.'[Deng, 2018] Therefore, vocational colleges should fully integrate the skill training resources of their own school and the practice base, strengthen the practical skill 
training for new teachers, make the new teachers of vocational colleges use both hands and brains, integrate knowledge and practice, establish the craftsman spirit at the beginning of their career, integrate their own professional theoretical knowledge and practical ability, and continue to professionalize and grow into the master of craftsmen in a large country.

\section{School-Based Training Path}

At present, the school-based training for new teachers in Chinese vocational colleges mainly includes teacher symposium, tutorial system, mutual help team, discussion and research groups, arranging excellent teachers to show excellent cases, inviting educational experts to hold lectures, etc. However, due to the fact that the organizers do not pay attention, the enthusiasm of new teachers to participate is not high enough, and the training activities are lack of management, these simple and easy traditional training methods are easy to fall into formalization, so the school-based training is difficult to achieve substantive results. In order to realize the substantive development of school-based training for new teachers, we should strengthen it from the following three aspects.

\subsection{Strengthen the Construction of Organizational System}

For the school-based training of new teachers, first of all, we should give full play to the functions of teacher training departments in Vocational Colleges and strengthen the top-level design at the school level. In order to avoid the lack of enthusiasm for new teachers' participation and the conflict between work and study faced by new teachers, vocational colleges should improve the institutional guarantee for the induction training of new teachers and ensure the learning time of young teachers. Secondly, we should take the school level training department as the center, radiate to all secondary departments, and implement training mechanism from school level and department level. "The training at the school level is relatively in place. Through the training, teachers have a basic understanding of the norms of teachers' ethics, school conditions, school history, educational laws and regulations, but there is still a lack of training at the discipline level. All professional departments should increase the special training for teachers in the school-based training." [Ren, 2020] Therefore, all secondary departments should implement corresponding training of their own specialty according to the professional characteristics of new teachers, so as to improve the professional ability of new teachers. Finally, we should establish a school-based training system for teachers in vocational colleges, and implement continuous training for teachers in various disciplines and stages to ensure the lifelong professional growth of teachers.

\subsection{Integrate Training Resources}

Vocational colleges should fully integrate training resources inside and outside the school and all over the country. First of all, in order to ensure the quality of school-based training for new teachers, vocational colleges must fully develop their own training resources and integrate excellent resources all over the country to build a stable training team with virtue, reasonable structure, and high responsibility through the combination of online and offline training. "The profound knowledge, noble ethics and exquisite ability of teachers can have a strong attraction and appeal to young teachers in the process of school-based training." [Zhou \& Xiong, 2008] 
Secondly, teachers from vocational colleges should have the characteristics of vocational skills. During the school-based training, the colleges should make full use of the enterprise practice resources, and enable new teachers to learn advanced production processes, cutting-edge technologies and key skills in relevant industries in the practice base, which has always been the weakness of Chinese vocational education. "The type and attribute of vocational colleges determines that the enterprise is an important implementation subject of double qualified teacher training." [Xie, 2021] "The success of" double qualified "teacher training in the United States, Australia and Germany is inseparable from the cooperation with enterprises. China should learn from the joint teacher training mode of schools and enterprises in the United States, Australia and Germany and improve the school-enterprise cooperative training system." [Hua $\& \mathrm{Gu}, 2022]$ Through the integration of school and enterprise resources in school-based training for new teachers, we can comprehensively improve the professional skills and professional ability of new teachers, which is good for building a high-quality double qualified teacher team.

\subsection{Innovate Training Mode}

The school-based training for new teachers should have both inheritance and innovation. For China, which has a long history of apprenticeship culture and attaches importance to human relations, the training of new teachers in vocational colleges should still establish and improve the mentoring mechanism. Through the tutorial system of master with apprentice, new teachers can learn and improve their teaching ability in teaching practice by listening to the masters' classes or assisting classes under the leadership of experienced teachers. At the same time, experienced teachers provide guidance and assistance to new teachers in scientific research, so that new teachers can overcome difficulties and enter the profession quickly. "New young teachers in colleges and universities are easy to fall into isolation due to their short entry time and unfamiliar with teaching work. The emergence of introductory tutors provides comprehensive support for the life and work of new teachers." [Zhu, 2016]

In addition, new teachers in vocational colleges are basically newly graduated graduates with high academic qualifications. They have excellent learning ability and rich theoretical knowledge. What they lack most is practical skills. Therefore, in school-based training, we should fully consider the characteristics and needs of new teachers and implement targeted training. "The urgent need of real life has become the main driving force of adult learning. Taking the present as the center and taking the problem as the center are the characteristics of adult learning." [Yang, 2019] Therefore, when training new teachers in vocational colleges, we can build a learning platform for new teachers based on Constructivist learning theory and guided by practical needs and problems, so as to promote new teachers to realize active construction in the created situation and generate new cognitive schema. Therefore, school-based training should enable new teachers to open their own thinking, think actively in the training process, strengthen the interaction among members and realize in-depth learning, so as to avoid the training floating on the surface and achieve better training effect.

\section{Conclusion}

This centralized induction training for novice teachers enables new teachers in vocational 
colleges to recognize the development trend of national and global vocational education, and establish the global vocational education concept and spirit to keep pace with the times. The training will stimulate the sense of honor and pride of new teachers as new members of vocational education, enhance their sense of integration and belonging in a new environment, which is beneficial for their professional growth. For the college, this kind of education for novice teachers will make colleges have more qualified teachers with rapid professional growth, which is good for the high-quality development of the college itself .For the country and society, they will obtain more high-quality talents with both theory and practical operation ability, so that it's conducive to social economy development. All in all, the school-based training for novice teacher closely link the teachers' personal destiny with the development of the vocational colleges and the country, which has great significance to implement the fundamental task of education for building morality and cultivating young people.

\section{Acknowledgement}

My special thanks go to my colleague, Professor Zhao Jianbin. His abundant knowledge and practical working experience of training teachers inspired me to finally finish this paper. I also want to thank my good friend, Huang Yan. I was under her encouragement and support to finish this paper.

\section{References}

Deng, Z. M. (2012). The Evolution of Teaching Content and Organization of Vocational Education in China. Journal of Shanxi University (Philosophy and Social Sciences Edition), 4, 120-124.

Deng, Z. M. (2018). The Necessary Path and Policy Choice for the Construction of Professional Teachers in Vocational Education. Vocational Education Forum, 3, 81-82 + 100 .

Hua, P., \& Gu, Z. (2022). X.Research on Optimizing the Training Path of "Double Qualified" Teachers in Higher Vocational Colleges -- an Analysis Based on Professional Characteristics ]. Higher Vocational Education Exploration, 21(1), January 2022.

Qu, B. K. (1991). Anthology of Pedagogy. British Education Reform. Beijing: People's education press.

Ren, H. H. (2020). Analysis on the Current Situation and Path of School-based Training in the Pre- job Training of New Teachers in Colleges and universities in Jiangsu in the New Era. Modernization of education, 53, July 2020.

Shan, Z. H. (2012). International Comparison of Teachers' Professional Development. Beijing: Educational Science Press.

Tang, Y. G. (2008). Teacher Professional Development and Teacher Education. Hefei, Anhui: Anhui Education Press.

Xie, J. (2021) .Characteristics and Enlightenment of "Double Qualified" Teacher Training in the United States, Australia and Germany. Vocational Education Newsletter, No. 12, 2021. 


\section{Macrothink}

Journal of Social Science Studies

ISSN 2329-9150

2022, Vol. 9, No. 1

Zhou, M., \& Xiong, S. Y. (2008). School-based Training Model and the Specialization of Young Teachers in Colleges and Universities. China Youth Research, 8, 2008.

Zhu, J. S. (1990). On Higher Education. Wuhan: Huazhong University of Technology Press.

Zhu, L. H. (2016). Analysis on the Current Situation of New Teacher Training in Colleges and Universities in China. Journal of Jilin Institute of education, 32(1), 2016.

\section{Web References}

Opinions on Comprehensively Deepening the Reform of Teachers' Quality Construction in the New Era [EB / OL] Website of the government of the People's Republic of China, B/OL] 。 Retrieved from http://www.gov.cn/zhengce/2018-01/31/content_5262659.htm

Yang, Guorong, A National Model Teacher: Philosophy Is "Useless and Useful", We Should Think Independently and Pay Attention to the Present. [EB/OL]. Retrieved from http://www.sh.xinhuanet.Com/2019-12/14/c_ 138631528.htm

\section{Copyright Disclaimer}

Copyright for this article is retained by the author(s), with first publication rights granted to the journal.

This is an open-access article distributed under the terms and conditions of the Creative Commons Attribution license (http://creativecommons.org/licenses/by/4.0/). 